\title{
La responsabilidad de los administradores frente a los accionistas de diferente clase con intereses contrapuestos* $^{*}$
}

\section{IJuan Antonio Gaviria Gil ${ }^{* *}$}

RESUMEN. En contraste con la pregunta sobre si se debe maximizar el patrimonio social o tratar igualitariamente a accionistas y otros grupos de interés, el interrogante sobre la responsabilidad de los administradores en sociedades con diferentes clases de acciones ha sido objeto de poca atención en Colombia. ¿Puede preferirse a algunos accionistas o debe tratarse a todos ellos equitativamente? Este artículo concluye que se debe preferir a los accionistas ordinarios cuando una decisión implique un conflicto entre estos y accionistas preferenciales. Empero, en relación con acciones de voto múltiple, de seguimiento o de pago debe tratarse equitativamente a todos los accionistas.

Palabras Clave: administrador, análisis económico del derecho, responsabilidad, sociedades.

* Fecha de recepción: 31 de enero de 2020. Fecha de aceptación: 14 de agosto de 2020.

Para citar el artículo: GAVIRIA GIL, J. A., "La responsabilidad de los administradores frente a los accionistas de diferente clase con intereses contrapuestos", Revista de Derecho Privado, Universidad Externado de Colombia, n. ${ }^{\circ} 40$, enero-junio 2021, 363-392, Dor: https://doi.org/10.18601/01234366. n40.13.

** Universidad Pontificia Bolivariana sede Medellín, Medellín, Colombia; miembro del grupo de investigaciones en Derecho. Doctor en Ciencias Jurídicas, American University Washington College of Law, Washington D.C., Estados Unidos. Contacto: juan.gaviriag@upb.edu.co Orcid: 0000-00029221-8642. 


\title{
The Managers' Duty of Giving Equal Treatment to Shareholders in Business Associations with Several Kinds of Shares. Can Managers Serve Two Masters with Conflicting Interests without Breaching Fiduciary Duties?
}

\begin{abstract}
AвstRAct. While whether managers and directors shall maximize equity or give equal treatment to shareholders and stakeholders is a well-studied question, the analysis of liability where two or more kinds of shares have been issued is almost inexistent in Colombia. May managers and directors prefer some shareholders or shall they give equal treatment to all? This paper concludes that they shall prefer common shareholders regarding decisions entailing conflicts of interests between the former and preferred shareholders. In contrast, and as to dual-class shares, tracking shares and stock received as payment for services, managers and directors shall treat equally all shareholders.
\end{abstract}

KEYwORDS: corporations, Law \& Economics, liability, managers.

Sumario. Introducción. I. Responsabilidad de los administradores en sociedades con acciones con voto múltiple. II. Responsabilidad de los administradores en sociedades con acciones preferenciales y sin derecho a voto. III. Responsabilidad de los administradores en sociedades en las que coexisten acciones ordinarias y otro tipo de acciones diferentes a las de voto múltiple y a las preferenciales sin derecho a voto. Conclusiones. Referencias.

\section{Introducción}

De vieja data es la discusión de si tanto los miembros de junta directiva, en caso de existir, como los representantes legales de una sociedad deben privilegiar el interés de los accionistas ${ }^{1}$, subordinando a ellos el beneficio de los demás grupos de interés, o si, por el contrario, deben tratar a unos y otros por igual. Argumentos a favor de una y otra posición abundan, siendo los más sobresalientes los que se derivan de la célebre sentencia en el caso Dodge v. Ford ${ }^{2}$, así como la famosa frase de Milton

1 Sanín considera que la palabra "asociados" engloba tanto a (i) partícipes, los propietarios de partes de interés en sociedades colectivas, (ii) socios, los dueños de cuotas en sociedades como la de responsabilidad limitada o la comandita simple, y (iii) accionistas, los titulares de acciones en sociedades cuyo capital se divide en dichos títulos. Véase SANín, I., Un nuevo derecho societario, el propuesto desde el Estatuto Tributario, Medellín, Diké, 1999, 47-48. Dada la alta prevalencia en Colombia de sociedades por acciones y en especial de sociedades por acciones simplificadas, este artículo solo utiliza las palabras "acciones" y "accionistas" (o en forma general, "asociados"), dejando de lado los términos "partícipes", "socios", "partes de interés" y "cuotas". El término "compañía" se utiliza como sinónimo de "sociedad".

2 Véase Dodge v. Ford Motor Company, 204 Mich. 459, 170 N.W. 668 (Mich. 1919) (“As we have pointed out, and the proposition does not require argument to sustain it, it is not within the lawful 
Friedman a principios de los setenta sobre el deber de los administradores de maximizar utilidades ${ }^{3}$; y, en sentido contrario, tanto los escritos de Colin Mayer $^{4}$ como una reciente declaración de The Business Roundtable, un grupo de presidentes de las compañías más importantes del mundo ${ }^{5}$.

El autor de este texto considera que los administradores deben privilegiar a los accionistas sobre los demás grupos de interés dado que tal regla genera incentivos adecuados para que aquellos, como dueños residuales de los flujos de caja corporativos, asuman los riesgos propios de la actividad empresarial y maximicen el crecimiento y la rentabilidad de las compañías ${ }^{6}$.

Con todo, este polémico pero ya muy estudiado tema no es el eje central del presente artículo. Asumiendo que el deber principal de los administradores es con sus accionistas, surge una pregunta mucho menos estudiada pero de gran relevancia, y que sí constituye el tema central o problema que aborda este texto: ¿cuál es el régimen legal de responsabilidad de los administradores de sociedades regidas por el derecho colombiano con más de una clase o tipo de accionistas y, en particular, cuál es el patrón de conducta o los deberes que debe cumplir un administrador cuando los intereses de un grupo de accionistas son diferentes o colisionan con los de los restantes asociados? Por sociedades con más de una clase de títulos entiéndase aquellas que, además de las imprescindibles acciones ordinarias, también han emi-

powers of a board of directors to shape and conduct the affairs of a corporation for the merely incidental benefit of shareholders and for the primary purpose of benefiting others...").

3 Friedman, M., "The social responsibility of business is to increase its profits", [en línea], The New York Times Magazine, 1970, disponible en: http://umich.edu/ thecore/doc/Friedman.pdf [consultado el 2 de julio de 2020] ("In a free-enterprise, private-property system, a corporate executive is an employee of the owners of the business. He has direct responsibility to his employers. That responsibility is to conduct the business in accordance with their desires, which generally will be to make as much money as possible while conforming to their basic rules of the society, both those embodied in law and those embodied in ethical custom").

4 Véase, e.g., Mayer, C., Prosperity: Better Business Makes the Greater Good, Oxford, Oxford University Press, 2019. Véase también el reciente debate entre Colin Mayer, defendiendo la postura de que una sociedad debe administrarse en favor de todos los grupos de interés, y Lucian A. Bebchuk, quien considera que los administradores deben privilegiar los intereses de los accionistas. Capitalism The Great Debate - Stakeholder v Shareholder, disponible en: https://www.youtube.com/ watch?v=cUpyL1zVF50 - [consultado el 2 de julio de 2020].

5 Business Roundtable, Business Roundtable Redefines the Purpose of a Corporation to Promote 'An Economy That Serves All Americans', [en línea], 19 de agosto de 2019, disponible en: https://www. businessroundtable.org/business-roundtable-redefines-the-purpose-of-a-corporation-to-promotean-economy-that-serves-all-americans [consultado el 16 de abril de 2020] ("While each of our individual companies serves its own corporate purpose, we share a fundamental commitment to all of our stakeholders"). Véase también Stout, L., The Shareholder Value Myth: How Putting Shareholders First Harms Investors, Corporations, and the Public, New York, Berrett-Koehler, 2012. En el contexto colombiano, véase SABOGAL, L. F., "El 'interés social': apuntes teóricos en el marco socioeconómico del derecho de empresa", Revista e-mercatoria n. ${ }^{\circ}$ 10, 2011.

6 Sobre este tema también puede consultarse el libro Creative Capitalism, en el cual diversos autores de renombre se refieren a los posibles deberes que deban tener las compañías con la sociedad en general. Véase Kinsley, M. (ed.), Creative Capitalism, A Conversation, New York, Simon \& Schuster, 2008. 
tido al menos alguna de las siguientes acciones: (i) privilegiadas (art. 381 c.com.), (ii) preferenciales sin derecho a voto (arts. 61 a 66 de la Ley 222 de 1995), (iii) con dividendo fijo (art. 10 de la Ley 1258 de 2008), (iv) con voto múltiple (ibíd.), (v) de clase (ibíd.) o (vi) de pago (ibíd.).

La respuesta al interrogante del párrafo anterior no es difícil cuando las decisiones de los administradores benefician o perjudican a todos los accionistas por igual, sin importar las características de sus títulos. En tal caso, es claro que los administradores deberán hacer su mejor esfuerzo para maximizar el patrimonio social, sin que tal labor tenga la potencialidad de privilegiar a unos accionistas sobre otros. En contraste, la pregunta se vuelve más compleja y de mayor interés académico cuando los administradores deben elegir entre una decisión A que beneficia a ciertos tipos de accionistas y perjudica a otros o una decisión B, que genera el efecto contrario.

Tal escenario puede presentarse para cualquier compañía que tenga diferentes clases de asociados. Recuérdese que las normas que permiten a las sociedades tener asociados de diferentes categorías no son tan nuevas. Tal posibilidad ha existido de tiempo atrás, incluso desde antes de la expedición del actual código de comercio ${ }^{7}$, para las sociedades en comandita, donde coexisten socios gestores y comanditarios $^{8}$. Podría suceder, por ejemplo, que ciertas decisiones sean convenientes para los gestores, al limitar el riesgo empresarial y comprometer menos su responsabilidad ilimitada, pero poco atractivas para los comanditarios por la baja rentabilidad esperada; o viceversa.

A pesar de la existencia de este antecedente, la dualidad de accionistas se ha vuelto más relevante desde que las leyes 27 de 1990 y 222 de 1995 permitieron las acciones preferenciales sin derecho a voto y, todavía más, desde que la Ley 1258 de 2008 (i) permitió las acciones de clase, de voto múltiple y de dividendo fijo ${ }^{9}$, (ii) ratificó la legalidad de las acciones de pago (ya permitidas desde antaño por el artículo 129 del Código Sustantivo del Trabajo) e (iii) hizo más flexibles los requisitos de las preferenciales sin derecho a voto ${ }^{10}$.

A medida que estas diferentes clases de acciones se vayan popularizando, el tema de este artículo se hará cada vez más relevante. Todavía no hay jurisprudencia

7 Véase Puyo, R., "Los diez grandes capítulos de la legislación de las sociedades comerciales en Colombia”, en REYEs, F. (coord.), Estudios sobre la sociedad por acciones simplificada, Bogotá, Universidad Externado de Colombia, 2010, 247-295

8 Véase, en general, sentencia de la Superintendencia de Sociedades del 20 de octubre de 2019, Gina Maritza Leguizamón Barbosa versus Luz Amanda Leguizamón Barbosa, Rolando Leguizamón Barbosa e Inversiones Leguizamón Barbosa \& Cía. S. en C.

9 Véase ReYes, F., La sociedad por acciones simplificada, Bogotá, Legis, 2009, 85 (afirmando que las acciones con dividendo fijo permiten una asimetría entre el porcentaje accionario y los dividendos que se reciben, de tal manera que un accionista pueda recibir, en años de resultados malos, un dividendo fijo y, en bonanzas, un dividendo superior pero menor al que reciben los demás accionistas).

10 Véase, en general, SANín, I., "La Ley sAS remoza las sociedades comerciales (y crea, también, nuevos retos)”, en ReYEs, F. (ed.), Estudios sobre la sociedad por acciones simplificada, Bogotá, Universidad Externado de Colombia, 2012, 62-64. 
sobre responsabilidad de los administradores en caso de decisiones que generen conflicto entre diversas clases de accionistas, pero tal casuística probablemente surgirá pronto debido al ritmo de cientos de demandas presentadas anualmente ante la Delegatura de Procedimientos Mercantiles de la Superintendencia de Sociedades ${ }^{11}$, más algunos cuantos procesos arbitrales societarios ${ }^{12}$. Aunado a lo anterior, la academia no debe esperar a que tales casos surjan, sino que es su deber analizar la materia con la mayor prontitud y rigurosidad.

Este escrito se basa en una metodología de investigación documental que analiza la poca normativa, jurisprudencia y doctrina colombiana existente con relación al problema ya descrito, y en la que el autor da su opinión sobre cómo se deben interpretar tales fuentes formales. Debido al limitado número de normas en el derecho colombiano, y con miras a llenar tal vacío, el artículo hace menciones no exhaustivas a la jurisprudencia y la doctrina de Estados Unidos. La relevancia mundial de este sistema jurídico y su mayor avance en cuanto al tema tratado hacen que tal mención sea ilustrativa para el estudio del caso colombiano y para la creación de doctrina y jurisprudencia en nuestro país en los próximos años, sin afectar tal conclusión, en estas épocas de globalización legal, el hecho de que el país elegido pertenezca a una cultura jurídica diferente a la colombiana.

Para complementar la descripción de la metodología del artículo se hacen necesarias algunas palabras sobre su alcance. Las conclusiones del presente escrito de investigación son aplicables a todo tipo de sociedades colombianas, tanto de capital concentrado como de capital disperso, e igualmente tanto a sociedades que han emitido acciones en bolsa como a aquellas que no lo han hecho. En cuanto a la primera de estas dos clasificaciones, los diferentes tipos de acciones aquí estudiados y los problemas que su coexistencia genera para los administradores y para los propios asociados pueden presentarse tanto en sociedades con un accionista controlante como en compañías en las que el capital está disperso en diferentes asociados sin que ninguno de ellos sea mayoritario. Por tal razón, el hecho de que en Estados Unidos sean más comunes las sociedades de capital disperso y menos frecuentes las de capital concentrado, al menos en cuanto a compañías que han emitido acciones en una bolsa de valores, no es obstáculo para tener como referente a dicho sistema jurídico en Colombia, a pesar de que en nuestro país el número de sociedades con acciones

11 Véase Revista Dinero, "La reivindicación de los accionistas minoritarios", [en línea], disponible en: https:/www.dinero.com/empresas/articulo/como-proteger-a-los-accionistas-minoritarios/276511 [consultado el 16 de abril de 2020].

12 Tómese tal frase como una posibilidad y no como un vaticinio. Podría suceder que, al menos en el corto plazo, no lleguen a existir tales litigios debido (i) a la poca acogida en la práctica de acciones diferentes a las ordinarias a lo mejor originada en los riesgos legales que su emisión o que la coexistencia con accionistas ordinarios genera para administradores y asociados, $\mathrm{o}$, en un escenario más implausible, (ii) a que tales acciones diferentes a las ordinarias sí se emitan pero sin que la coexistencia entre diferentes clases de asociados genere conflictos y litigios. 
inscritas en una bolsa de valores es ínfimo ${ }^{13}$. De todas maneras, el texto hará referencia a la responsabilidad de los administradores de sociedades con diferentes clases de acciones y con accionistas con intereses en conflicto, tanto para el caso en que los gestores son diferentes a los propios accionistas, como es común en compañías de capital disperso, como para el evento en que uno de los accionistas controla o incluso realiza directamente las labores propias de los administradores.

En conexión con lo anterior, el problema abordado en el texto es relevante tanto para sociedades en bolsa (la minoría en Colombia) como para sociedades cerradas (la mayoría), aunque con una advertencia: las acciones de clase, las de dividendo fijo y las de voto múltiple solo están permitidas para las sociedades por acciones simplificadas (art. 10 de la Ley 1258 de 2008), que por expresa disposición legal no pueden emitir acciones en bolsa (art. 4 ibíd.) ${ }^{14}$. Si bien la mayoría de compañías colombianas no cotizan en una bolsa de valores, ello no es un inconveniente para el análisis ${ }^{15}$. En contraste, las acciones privilegiadas, las preferenciales sin derecho a voto y las de pago sí podrían emitirse en cualquier tipo de sociedad, incluyendo a sociedades por acciones simplificadas y a sociedades anónimas.

Tampoco es óbice para considerar el derecho estadounidense como una guía para la interpretación de las normas societarias colombianas el hecho de que en aquel país, en comparación con el nuestro, los administradores tengan mayores facultades y los accionistas una menor injerencia en los asuntos de la compañía ${ }^{16}$. Aun en relación con decisiones que en el derecho colombiano la asamblea de accionistas o la junta de socios toma, ya sean frecuentes, como aquellas sobre repartición de utilidades, o bien relacionadas con cambios fundamentales de la compañía y por lo tanto ocasionales, como fusiones, escisiones y liquidaciones, los asociados suelen considerar como persuasivas las recomendaciones de los administradores. Sin perjuicio de lo anterior, hay muchas otras decisiones que, de conformidad con las normas legales o por delegación de los accionistas en los estatutos, los administradores

13 Desde el texto clásico de Berle y Means, Estados Unidos se ha considerado como un país en donde son comunes las sociedades de capital disperso sin accionista controlante y en las que sus beneficiarios reales suelen invertir a través de diferentes instrumentos financieros, como los ofrecidos por los fondos mutuos. Véase Berle, A. A. y Means, G. C., The Modern Corporation and Private Property, 2. ${ }^{\text {a }}$ ed., New York, Routledge, 1991. En Colombia, y en general en Latinoamérica, se ha afirmado por diferentes razones que las sociedades de capital disperso son más escasas, y más comunes las de capital concentrado. Véase Reyes, F., "Corporate governance in Latin America. A functional analysis", [en línea], Inter-American Law Review, vol. 39, n. ${ }^{\circ} 2,2008$, disponible en: http://ssrn. com/abstract=1005208 [consultado el 16 de abril de 2020]. Véase también Armour, J., EnRIQUEs, L., Pargendler, M. y Ringe., W. G., "Beyond the anatomy", en KraAkman, R. (ed.), The Anatomy of

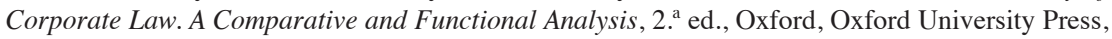
2009.

14 Ello a pesar de que el reciente Decreto Legislativo 817 de 2020 les permitió inscribir títulos de deuda en el Registro Nacional de Valores y Emisores y negociar estos en el segundo mercado.

15 Véase Moreno, A., La bolsa en Colombia en el siglo XXI, la evolución de los inversionistas y emisores de acciones de la Bolsa de Colombia en los últimos 20 años (1999-2018), Bogotá, 2018.

16 Bainbridge, S. M., Corporate Law and Economics, New York, Foundation Press, 2002. 
pueden tomar directamente y que, en algunos casos, benefician a unos accionistas y perjudican a otros (p. ej., incremento del endeudamiento cuando la compañía todavía tiene un patrimonio positivo pero inferior al existente un tiempo atrás cuando la situación económica era más favorable).

Como nota metodológica final, el texto analiza las normas legales colombianas como existen en la actualidad (lege lata), y entre ellas el código de comercio y las leyes 222 de 1995 y 1258 de 2008, sugiriendo la forma más eficiente de interpretarlas por parte de los jueces, árbitros y, en general, de los operadores jurídicos, pero sin considerar necesarios ni proponer cambios legislativos.

Habiendo dejado claro el problema jurídico-económico que motiva este texto así como su metodología, resta indicar su estructura. La primera sección se refiere a la responsabilidad de los administradores cuando una sociedad ha emitido tanto acciones ordinarias como de voto múltiple. Como anotación sobre el alcance, esta parte del texto no hace referencia a figuras del derecho societario de legalidad discutida y que podrían tener finalidades similares a las de las acciones de voto múltiple, como las pirámides. La segunda sección continúa con el análisis de la responsabilidad de los administradores pero con relación a sociedades en las que coexisten acciones ordinarias y acciones preferenciales sin derecho a voto, siendo sus conclusiones también aplicables a las compañías que han emitido acciones con dividendo fijo. La tercera sección extiende el estudio a sociedades en que coexisten acciones ordinarias con otros tipos de títulos, como acciones privilegiadas, de seguimiento y de pago. La última sección resume los hallazgos del escrito, formula algunas conclusiones y sugiere algunas investigaciones posteriores que podrán profundizar los temas aquí tratados.

\section{Responsabilidad de los administradores en sociedades con acciones con voto múltiple}

Como su nombre lo revela, acciones de voto múltiple ${ }^{17}$ son aquellas que abandonan la regla tradicional de un voto por acción para darle a su propietario $\mathrm{N}$ votos por cada título, siendo $\mathrm{N}$ un número positivo con $1<\mathrm{N}<\infty$, con la característica adicional de que $\mathrm{N}$ puede ser un número entero o un fraccionario. Ni el código de comercio, ni las normas que lo antecedieron o que lo han complementado permiten las acciones de voto múltiple para sociedades anónimas o para otro tipo de compañías ${ }^{18}$. Caso contrario al del artículo 10 de la Ley 1258 de 2008 que, sin nombrarlas expresamente y sin restringir ni el número de votos por título ni su vigencia, autoriza a las socieda-

17 El nombre en español es más claro y apropiado que en inglés (dual-class shares).

18 Véase artículo 381 c.com. ("En ningún caso podrán otorgarse privilegios que consistan en voto múltiple, o que priven de sus derechos de modo permanente a los propietarios de acciones comunes"). 
des por acciones simplificadas (SAS) a emitir tales acciones ${ }^{19}$. Dada la autorización escueta de la Ley 1258, serán los estatutos sociales de una SAs los que estipulen si tales acciones de voto múltiple existen y, en caso afirmativo, cuántos votos por acción dan a su titular, además de indicar si expiran o no, entendiéndose que el voto múltiple tendrá la misma duración de la compañía en caso de silencio estatutario.

Las acciones con voto múltiple pueden ser muy eficientes para todos o al menos parte de los accionistas de una compañía. De una parte, y en legislaciones diferentes a la colombiana, son viables en compañías que emiten acciones en bolsa, como ha sido la moda reciente ilustrada en casos como los de Google, Facebook y Lyft. El voto múltiple en una sociedad que ingresa a bolsa permite a sus accionistas fundadores obtener recursos frescos al tiempo que mantienen el control sobre sus creaciones empresariales y evitan una toma hostil sin necesidad de diseñar esquemas de protección costosos o sofisticados como píldoras venenosas y repelentes de tiburones.

De otro lado, las acciones con voto múltiple le permiten a su titular tener el control de una compañía a pesar de contar con una minoría accionaria, algo especialmente útil cuando el inversionista de marras quiere diversificar su riesgo financiero o cuando tiene mucho interés en el poder político pero poco en las utilidades de la compañía respectiva ${ }^{20}$. Es el caso típico de sociedades familiares en las cuales el padre o madre detenta un pequeño porcentaje manteniendo la mayoría de votos mientras sus hijos experimentan la situación opuesta: una mayoría en el capital pero con minoría en la democracia societaria ${ }^{21}$. En resumen, los padres pueden transferir la propiedad a sus hijos, pero conservando el control $^{22}$.

No se crea, con todo, que las acciones con voto múltiple en sociedades cerradas son útiles tan solo en contextos familiares. Dichas acciones también tienen la ventaja de permitir a los accionistas controlantes perseguir su visión idiosincrática, sin tener que justificar sus decisiones a los demás asociados, algo especialmente útil cuando

19 Aunque las sociedades de servicios públicos domiciliarios pueden ser SAs, la Superintendencia del ramo, en Oficio 220-081657 del 9 de junio de 2009, afirmó que, con base en el artículo 19.9 de la Ley 142 de 1994, tales compañías no pueden emitir acciones de voto múltiple. Francisco Reyes Villamizar critica esta doctrina; véase REYEs, F., La sociedad por acciones simplificada, Bogotá, Legis, 2009, 95, 189-190. El autor de este texto comparte dicha crítica.

20 Las acciones de voto múltiple no son la única forma de controlar una compañía a pesar de no tener el derecho a recibir la mayoría de sus flujos de caja. Otros métodos son las pirámides y las estructuras de propiedad cruzada. Véase Bebchuк, L. A., KraAkman, R. y Triantis, G., "Stock pyramids, cross-ownership and dual class equity: the mechanisms and agency costs of separating control from cash-flow rights", en Morck, R. (ed.), Concentrated Corporate Ownership, New York, University of Chicago Press, 2000, 445-560.

21 Véase Reyes, F., La sociedad por acciones simplificada, Bogotá, Legis, 2009, 95, 189-190. Esta función económica de las SAS con acciones con voto múltiple hace ya innecesarias las sociedades en comandita que en el pasado cumplían una función similar. Véase, en general, MENDOZA, J. M., “La comandita: R. I. P.", [en línea], Ámbito Jurídico, 4 de julio de 2019, disponible en: https://www. ambitojuridico.com/noticias/columnista-impreso/sociedades-y-economia-solidaria/la-comandita-ri-p [consultado el 2 de julio de 2020]. 
los frutos solo se verán en el largo plazo y cuando algunos accionistas se caracterizan por su impaciencia financiera ${ }^{23}$.

Como un beneficio adicional, las acciones de voto múltiple pueden ser usadas en sociedades de capital disperso que carecen de accionista mayoritario. En este tipo de compañías, y por problemas de acción colectiva, es posible que ningún accionista considere rentable supervisar a los administradores, quienes a sabiendas de ello podrán aprovechar la laxa vigilancia para procurar más su beneficio personal que el de la compañía. La solución a tal problema podrá consistir en otorgar un voto múltiple a uno de los accionistas, que mantendrá su participación baja aunque quizás ligeramente incrementada como recompensa, para que así tenga incentivos y poder para controlar a la gerencia con el consiguiente beneficio para todos los accionistas.

Pero no todo es color de rosa: las acciones de voto múltiple tienen su lado oscuro, generando riesgos que podrán ser a veces mayores que sus beneficios y agravando los conflictos de agencia entre diferentes tipos de accionistas ${ }^{24}$. Como principal riesgo, el voto múltiple les otorga a los accionistas con tales derechos políticos aumentados, así como a los administradores que ellos elijan, un incentivo para expropiar los activos y flujos de caja de la sociedad que es concomitante con un menor interés en la maximización de utilidades. Tal riesgo, sobra decirlo, es mayor mientras menos protector de los demás accionistas sea el régimen legal ${ }^{25}$. Así, accionistas con voto múltiple, baja participación accionaria y poca honestidad se podrán preguntar:

23 Véase, en general, Goshen, Z. y Hamdani, A., "Corporate control, dual class, and the limits of judicial review”, Columbia Law Review, vol. 120, n. ${ }^{\circ}$ 941, 2020, 94 (indicando las ventajas de las acciones de voto múltiple al permitir a los accionistas controlantes perseguir su visión idiosincrática, pero advirtiendo los riesgos de violación al deber de lealtad que generan y la respuesta que deben dar las cortes ante conflictos entre accionistas).

24 Lucian Bebchuk es el principal crítico de las acciones de voto múltiple, especialmente cuando son perpetuas y emitidas por sociedades inscritas en una bolsa de valores. Sus dos escritos más relevantes sobre el tema son: Bebchuk, L. A. y Kastiel, K., "The untenable case for perpetual dual class stock", Virginia Law Review, vol. 103, n. 4, 2017, 585, y Beвchuк, L. A. y Kastiel, K., "The perils of small minority controllers", Law Working Paper - ECGI Working Paper Series in Law, n. ${ }^{\circ}$ 434, 2018. En contra de Bebchuk y Kobi, véanse Sharfman, B. F., "The undesirability of mandatory time-based sunsets in dual class share structure: a reply to Bebchuk and Kastiel", Southern California Law Review Postscript, vol. 93, 2019, 1 (argumentando que las acciones de voto múltiple sin límite de tiempo son eficientes y que por lo tanto la ley no debe restringir su duración), y Kim, H. y Michaely, R., "Sticking around too long? Dynamics of the benefits of dual-class voting", [en línea], European Corporate Governance Institute (ECGI) - Finance Working Paper n. ${ }^{\circ}$ 90, 2019, disponible en: https://ecgi.global/working-paper/sticking-around-too-long-dynamics-benefits-dualclass-voting [consultado el 16 de septiembre de 2020] (reportando, con base en un estudio empírico, que la mayoría de límites temporales a las acciones de voto múltiple son inocuos).

25 Véase, en general, La Porta, R. Lopez, F., Shleifer, A. y Vishny, R., "Law and finance”, Journal of Political Economy, vol. 106, n. ${ }^{\circ}$ 6, 1998, 1113 (reportando los resultados de un estudio empírico según el cual la protección de los inversionistas minoritarios depende del régimen legal). Véase también Gurrea-Martínez, A., "Theory, evidence, and policy on dual-class shares: a country-specific response to a global debate", Ibero-American Institute for Law and Finance, Working Paper Series n. ${ }^{\circ}$ 3, 2019 (afirmando que las acciones de voto múltiple en compañías inscritas en bolsa deben ser permitidas en países con una fuerte protección legal pero prohibidas o sujetas a significativas restricciones en países con mercados y reguladores menos sofisticados). 
¿el poder para qué?, para luego contestarse a sí mismos: para enriquecerse y vivir como emperadores asistidos por una nutrida burocracia en la sociedad que controlan. Tales accionistas con voto múltiple podrán igualmente estar interesados en mantener mejores relaciones con proveedores, empleados, acreedores y otros grupos de interés que con los propios accionistas ordinarios. Aunque es positivo que los administradores les den un buen trato a tales grupos de interés, sí puede ser grave que los aportes de los accionistas se gasten descuidadamente con el objeto de intentar complacer o cautivar a aquellos.

Desde luego, las acciones descritas en el párrafo anterior implicarán una violación de los deberes fiduciarios de los miembros de junta directiva (si este órgano existe) y representantes legales, así como de los accionistas controlantes en su papel de administradores de hecho, pero tal posibilidad puede no ser suficiente disuasor de la expropiación ya descrita en caso de que su beneficio sea mayor al valor esperado de la sanción en un proceso legal (cuantía multiplicada por la probabilidad).

Ciertamente, el riesgo de expropiación y en general de incumplimiento de los administradores de sus deberes también existe cuando no hay acciones de voto múltiple, pero en tal caso el peligro es menor porque los accionistas mayoritarios y sus gestores saben que todo peso gastado es un peso menos en dividendos, del cual ellos dejarán de recibir un significativo porcentaje. Un accionista ordinario con el 51\% del capital pierde 51 centavos de cada peso derrochado, mientras que un accionista con, por ejemplo, solo el $5 \%$ del capital pero control político gracias a su voto múltiple pierde solo 5 centavos. Los incentivos son muy diferentes en uno y otro caso.

Queda pues claro que las acciones de voto múltiple crean graves problemas de agencia entre sus titulares y los accionistas con voto unitario al divergir los intereses de ambos grupos. Sobra decir que mientras más pequeña sea la participación del accionista con voto múltiple o mayor su número de votos, más grave será el problema descrito. A modo de ilustración, los problemas de agencia en una sociedad cuyo accionista controlante tiene el $20 \%$ de los derechos económicos pueden ser mucho más del doble que en una compañía en donde tal cifra es del $40 \%$.

En Colombia, dado el silencio legislativo y bajo el principio de que los particulares pueden hacer todo aquello que no está prohibido (art. 6 de la Constitución Política), las acciones de voto múltiple pueden existir desde la constitución de la SAS en cuestión o aprobarse en un momento posterior, con motivo de una capitalización o de otro tipo de reforma estatutaria. En general, los riesgos inherentes a las acciones con voto múltiple son mayores en este segundo evento. Después de todo, las cláusulas de los estatutos en la constitución de una sociedad se aprueban por unanimidad mientras que, cuando la sociedad ya está en marcha, los accionistas mayoritarios pueden imponer la reforma a los minoritarios ${ }^{26}$. A pesar de tal peligro, la Ley 1258

26 Véase el artículo 68 de la Ley 222 de 1995, el cual requiere la mayoría de las acciones representadas para aprobar una decisión, salvo que los estatutos estipulen una cifra superior. 
de 2008 no exigió unanimidad para reformas estatutarias que crean o modifican acciones con voto múltiple (cfr. art. 41).

Como riesgo adicional, las acciones con voto múltiple pueden perpetuar o atrincherar dinastías societarias ${ }^{27}$. En efecto, los accionistas con voto múltiple pueden mantener su poder hasta morir y luego de ello ser reemplazados por sus herederos, como si fueran reyes ${ }^{28}$. Ello no parece grave en sociedades de familia: al fin y al cabo allí las acciones de voto múltiple se utilizan para facilitar una transición generacional. Pero sí es un tema de cuidado en sociedades que cotizan sus acciones en bolsa (en caso de que en el futuro ello se permita en Colombia $)^{29}$ o incluso en sociedades cerradas no familiares o también de familia pero constituidas hace muchas décadas y con muchos accionistas. El problema se agrava porque si bien el accionista con voto múltiple puede haber sido, por sí o por interpuesta persona, un administrador honesto y eficiente en su apogeo, puede que en su vejez ya no lo sea, o que se produzca su reemplazo por un heredero incompetente o fraudulento ${ }^{30}$.

Para evitar tal riesgo, los estatutos de una SAS pueden pactar las denominadas “cláusulas atardecer". En tal caso, la duración de las acciones con voto múltiple no será indefinida y ni siquiera igual al plazo de la sociedad en caso de que este sea finito, sino que las mismas perderán su poder mágico, volviendo al voto unitario, cuando se cumpla determinado plazo o condición ${ }^{31}$. Ejemplos de ello podrían ser la enajenación de las acciones, la muerte del accionista o, para evitar discusiones sobre la legalidad de tal condición, su llegada a cierta edad. Si bien las cláusulas atardecer minimizan el riesgo de atrincheramiento ya descrito, crean otro tipo de desventajas, principalmente el incentivo para el accionista de voto múltiple de actuar de manera oportunista y expropiar la sociedad de marras justo antes de que su poder expire, en un típico ejemplo del problema del juego final que ha sido descrito por la literatura del análisis económico del derecho ${ }^{32}$.

Tal vez debido a los riesgos descritos anteriormente, y a pesar de no conocer estadísticas sobre el tema, la intuición indica que las acciones con voto múltiple todavía no son muy comunes en Colombia. Si ser accionista minoritario en una sociedad sin tal tipo de acciones es riesgoso, el peligro es todavía mayor en una con acciones con voto múltiple. Igual de peligroso será ser administrador de una de estas compañías: si el accionista con voto múltiple quiere expropiar la compañía, el gestor

27 Véanse Beвсhuк, L. A. y Kastiel, K., “The untenable case for perpetual dual class stock", Virginia Law Review, vol. 103, n. . 4, 2017, 585, y Bевснuк, L.A. y Kastiel, K., "The perils of small minority controllers", Law Working Paper - ECGI Working Paper Series in Law, n. ${ }^{\circ}$ 434, 2018.

28 Véase ibíd.

29 Véase ibíd.

30 Véase ibíd.

31 Véase Oficio 220-085176 de 2009 de la Superintendencia de Sociedades.

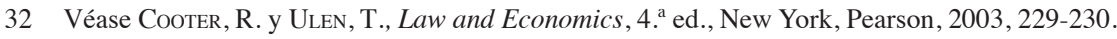


será un títere que comprometerá su responsabilidad, pero si se niega a ello, podrá perder su empleo.

Su poco uso, sin embargo, no es equivalente ni a inexistencia ni a que tal tendencia no pueda revertirse en el futuro. Para sociedades presentes o futuras que hayan emitido acciones con voto múltiple, este texto considera que los administradores deben tratar por igual a los accionistas que gozan de voto ampliado y a los accionistas ordinarios; al fin y al cabo, dichas acciones con voto múltiple modifican los derechos políticos pero no los económicos.

\section{Responsabilidad de los administradores en sociedades con acciones preferenciales y sin derecho a voto}

Las acciones preferenciales sin derecho a voto tienen dos diferencias básicas con las ordinarias que se hacen evidentes al observar su denominación: la preferencia, el beneficio o quo, y la imposibilidad de votar en las asambleas, el sacrificio o quid ${ }^{33}$. Tales características hacen que las acciones preferenciales sean un híbrido o mezcla entre deuda y patrimonio, una especie de anfibio societario ${ }^{34}$.

La preferencia implica que la sociedad en cuestión no puede pagar dividendos a los accionistas ordinarios hasta que se haya pagado una suma mínima o proporcional a los preferenciales, de conformidad con las estipulaciones estatutarias ${ }^{35}$. Lo mismo ocurre con el reembolso de aportes en una eventual liquidación de la compañía.

La renuncia al voto, a su vez, no suele ser un mayor sacrificio para los accionistas preferenciales. Ser accionista minoritario con voto en una sociedad con un accionista controlante genera casi el mismo poder político (nulo) que ser accionista minoritario preferencial sin voto en una compañía similar, a menos que los estatutos hayan pactado súper mayorías para las decisiones sociales más importantes o que implican cambios fundamentales.

De tal manera, emitir acciones preferenciales sin derecho a voto puede resultar eficiente y beneficioso tanto para accionistas ordinarios como para accionistas preferenciales: aquellos obtienen recursos frescos para la compañía que controlan sin ne-

33 Véase, en general, Gaviria, E., Nuevo régimen de sociedades, comentario general, Medellín, Diké, 1996, 156 (afirmando que el accionista preferencial no solo carece del derecho al voto sino que tampoco puede asistir a las asambleas de accionistas, a menos que sea expresamente invitado).

34 Véase Bainbridge, S. M., Corporate Law, 3. a ed., New York, Foundation Press, 2015, 37 ("Preferred stock is an odd beast, neither wholly fish nor wholly folly, which lies on the boundary between debt and equity").

35 Luego de pagado el dividendo a los preferenciales, lo común es que el resto de las utilidades se distribuya como dividendo a los accionistas ordinarios. Pero también puede pactarse en los estatutos que las preferenciales tengan cierto dividendo mínimo (si hay utilidades) y, luego de eso, que compartan el resto de dividendos con los accionistas ordinarios. Una variante de las acciones preferenciales sin derecho a voto son las de dividendo fijo en las que se promete una suma fija anual a ciertos accionistas, a condición de que haya utilidades, pero sin que estos renuncien al derecho al voto. Véase, en general, ReYEs, F., La sociedad por acciones simplificada, cit., 85. 
cesidad de ceder o compartir el poder, algo especialmente útil cuando sus mayorías son ligeramente superiores al 50\%, mientras que estos últimos reducen el riesgo financiero de su inversión a cambio de ceder un voto que de por sí poca utilidad tenía.

Similar a lo que sucede con las acciones de voto múltiple, las preferenciales no solo generan beneficios sino también riesgos. Para empezar, y en el raro caso en que el accionista preferencial sea también el administrador de la sociedad, este tendrá el incentivo de invertir los aportes en actividades empresariales de bajo riesgo, que sean apenas necesarias para generar la rentabilidad prometida a los accionistas preferenciales.

Más frecuente en Colombia será el escenario en el cual son los accionistas mayoritarios quienes directamente o por interpuesta persona administran la compañía. En tal caso, el incentivo será el contrario: empresas más riesgosas que en caso de ser exitosas generarán dividendos tanto para los accionistas preferenciales como para los ordinarios pero que en caso de fracasar no obtendrán utilidades repartibles. Al fin y al cabo y para los accionistas ordinarios, sería equivalente no generar utilidades y generarlas en un monto bajo. En este sentido, mientras mayor sea la promesa de dividendos preferenciales, mayor será el riesgo empresarial que quieran asumir los accionistas ordinarios y los administradores a quienes ellos nombren ${ }^{36}$.

Como ilustración, asúmase un caso extremo de una compañía sin pasivos y cuyo capital y patrimonio es de $\$ 100$, constituido por $\$ 50$ de acciones preferenciales y $\$ 50$ de acciones ordinarias ${ }^{37}$. Asúmase también que los activos se destinan a un pro-

36 Con todo, el incentivo no siempre es negativo: la existencia de acciones preferenciales podría motivar a los accionistas ordinarios y a sus gestores a ser más eficientes y a generar más utilidades, con el fin de generar dividendos a los accionistas ordinarios, en comparación con una sociedad sin accionistas preferenciales, en la cual la presión de obtener utilidades cuantiosas puede ser menor.

37 El artículo 61 de la Ley 222 de 1995 indica que las sociedades por acciones podrán emitir acciones preferenciales y sin derecho a voto siempre y cuando no representen más del $50 \%$ del capital suscrito. Una primera posición doctrinal consiste en considerar que esta norma aplica a tales tipos de acciones en las sociedades por acciones simplificadas de conformidad con el artículo 45 de la Ley 1258 de 2008 que aplica por remisión a las sAs las normas sobre sociedades anónimas. Una segunda posición doctrinal, que este autor comparte, considera que el límite para las acciones preferenciales sin derecho a voto de máximo el $50 \%$ del capital suscrito no es aplicable a las sas toda vez que en estas y según el propio artículo 45 de la Ley 1258, las disposiciones estatutarias tienen prelación sobre las normas comerciales que rigen las sociedades anónimas, como es el caso de la Ley 222 de 1995. Véase SANín, I., "La Ley SAS remoza las sociedades comerciales (y crea, también, nuevos retos)", en REYEs, F. (ed.), Estudios sobre la sociedad por acciones simplificada, Bogotá, Universidad Externado de Colombia, 2012, 62-64. Véase también Superintendencia de Sociedades, oficios 220-136893 del 11 de septiembre de 2018, 220-05723 de 2015 y 220-057533 del 26 de marzo de 2009 ("Tal primacía o prelación de las disposiciones estatutarias sobre las normas remitidas desde la sociedad anónima (aún las imperativas) permite válidamente estipular reglas estatutarias impensables como válidas hasta la vigencia de la Ley sAs...”). Así, por ejemplo, podría haber una sas con 100 acciones, 1 ordinaria y 99 preferenciales. Aunque el accionista ordinario tiene el monopolio del voto, los preferenciales podrían haber exigido al momento de la constitución y vía acuerdos contractuales control sobre la administración, algo lógico teniendo en cuenta que son los mayores interesados en la rentabilidad de la compañía. También podría suceder que los preferenciales tengan poco porcentaje sobre el capital y no hayan hecho tal exigencia pero que algunos de ellos sean nombrados administradores en consideración a sus capacidades de gestión o de conocimiento de la industria a la 
yecto que tiene un $50 \%$ de probabilidad de éxito y un 50\% de fracaso. Si el proyecto fracasa, no queda un peso para nadie. Si tiene éxito, los preferenciales tendrían un valor patrimonial de $\$ 50$, el mismo de antes, y los ordinarios de $\$ 150$, con lo cual habrán triplicado su valor. Un poco de matemática permite predecir que la apuesta empresarial tendrá sentido incluso si la probabilidad de éxito es tan baja como un $33,3 \%$. Con el agravante de que, a diferencia de los acreedores sofisticados que usualmente se protegen con covenants, a los preferenciales les resulta más difícil limitar tal clase de inversiones ${ }^{38}$.

El riesgo indicado existe porque la preferencia de las acciones preferenciales no implica obligación incondicional de la sociedad de pagar sumas anuales a sus titulares. Tal deber solo existe si hay utilidades ${ }^{39}$. Si, por el contrario, la compañía da pérdidas ocurrirá uno de los dos siguientes escenarios, de conformidad con lo estipulado en los estatutos ${ }^{40}$ : (i) los dividendos se perderán para los accionistas preferenciales, al no ser acumulables (morirán, o mejor dicho, nunca habrán nacido), o (ii) sin son acumulativos, el valor que deberá pagar la sociedad al siguiente año se duplicará, condicionado a que en ese momento haya utilidades suficientes. Con relación a este segundo escenario, mientras mayor sea la suma acumulada que haya que pagar a los preferenciales, más altas tendrán que ser las utilidades para generar un remanente para los accionistas ordinarios, lo que a su vez aumentará la propensión al riesgo de estos, en claro contraste con la natural aversión al riesgo de los preferenciales. Supóngase una compañía que lleva 10 años sin pagar dividendos preferenciales acumulativos y cuyo monto es cercano al valor de la empresa en marcha ${ }^{41}$. En casos como estos, los accionistas ordinarios y sus administradores saben que poco hay que

que pertenece la compañía. Para un caso en que los accionistas preferenciales tenían control sobre la junta directiva, por estipulación estatutaria, véase In re Trados Incorporated Shareholder Litigation 73 A.3d 17 (Del. Ch. 2013).

38 Véase Bainbridge, S. M., Corporate Law, 3. a ed., New York, Foundation Press, 2015, 257. (“[B]ond indentures are hundreds of pages long and deal with virtually every conceivable contingency. In contrast, preferred stock certificates of designation tend to be relatively short and to deal with only a few issues. Which leaves unresolved a nagging question; namely, how you do deal with issues that come up that the contract does not cover? The answer, by analogy to the bond setting, is to use an implied covenant of good faith rather than fiduciary duties. In this context, such a covenant would preclude the board from taking action that deprives the preferred of the benefit of the bargain. To the extent that covenant fails to provide adequate protections, portfolio theory teaches that the preferred stockholders should engage in self-help by diversifying their portfolio").

39 Véase Oficio 220-43349 de la Superintendencia de Sociedades del 30 de octubre de 2001 (afirmando que el dividendo de las acciones con derecho preferencial se pagará siempre que la sociedad genere utilidades de fin de ejercicio). En igual sentido, Oficio 220-43152 de la misma entidad y fecha.

40 Ante lo escueto de las normas existentes (arts. 61 a 66 de la Ley 222 de 1995, que son normas supletivas para las SAS), las acciones con dividendo preferencial o con dividendo fijo se rigen por los estatutos. Véase Oficio 220-087094 de 2009 de la Superintendencia de Sociedades.

41 Los hechos de este ejemplo se basan en el caso Bove v. Community Hotel Corp 105 R.I. 36 (R.I. 1969). Allí la corte de Rhode Island validó la exclusión por medio de una fusión por parte de la compañía de accionistas preferenciales a quienes no les habían sido pagados dividendos acumulables durante 24 años. 
perder si las apuestas empresariales salen mal y mucho que ganar si resultan bien. Es como tener una opción financiera con pérdidas limitadas a los aportes ya hechos (el valor de la prima de la opción) y con ganancias ilimitadas. Por eso se dice que las acciones preferenciales suelen funcionar muy bien en compañías exitosas pero no tanto en compañías que, sin estar todavía insolventes, no generan suficiente utilidad o caja para pagar dividendos ${ }^{42}$.

Dividendos preferenciales, como ya se dijo, solo son pagables si la compañía genera utilidades. Esta es la diferencia clave con los contratos de empréstito. Tal característica genera otro riesgo: los accionistas mayoritarios, directamente o a través de sus gestores, pueden incurrir en conductas de expropiación o en el denominado tunneling ${ }^{43}$ ante el temor de que las utilidades solo alcancen para pagar a los accionistas preferenciales o previendo que alcancen para todo tipo de accionistas pero queriendo perjudicar a aquellos. Así, los administradores y los accionistas controlantes se esfuerzan por hacer rentable la compañía pero los excedentes contables y de caja los trasladan directamente a sus bolsillos mediante contratos laborales, de prestación de servicios o de compra de bienes con sus propias compañías y a precios muy favorables para estas. Al final del ejercicio, aquellos les reportarán a los accionistas preferenciales lo siguiente: "a pesar de que nos esforzamos mucho, la utilidad fue $0 \mathrm{o}$ mínima", y los consolarán diciendo que al menos eso permitió no pagar impuesto de renta, especialmente en una época en que la renta presuntiva tiende a desaparecer ${ }^{44}$.

La preferencia de los accionistas preferenciales no es solo frente a los dividendos que la sociedad distribuya durante su existencia sino también con respecto al reembolso de sus aportes cuando la compañía se liquide. A primera vista, tal prelación parece disminuir el riesgo de que los aportes no se recuperen; con todo, un análisis más detallado lleva a concluir que esta precedencia termina siendo (i) inocua si la compañía es muy rentable o (ii) riesgosa en el caso de una sociedad al borde de la insolvencia.

En el primer escenario, los accionistas mayoritarios y/o ordinarios no tendrán incentivos para disolver y liquidar una sociedad exitosa, más aún si su término de duración es de muchos años ${ }^{45}$ o, como es permitido y común en las SAs, indefinido.

42 Graham, B. y Dodd, D., Security Analysis, The Classic 1940, 2. a ed., New York, McGraw-Hill, 2019, 184-206, 261-265.

43 Véase Johnson, S., La Porta, R., Lopez, F. y Shleifer, A., "Tunneling”, The American Economic Review, vol. 90, n. ${ }^{\circ}$ 2, 2000, 22-27 (definiendo tunneling como "the transfer of resources out of a company to its controlling shareholder (who is typically also a top manager"). La transferencia puede ser de flujos de caja, de activos o de valores patrimoniales. Véase también AtanAsov, V., BLACK, B. y Ciccotello, C., "Unbundling and measuring tunneling", University of Illinois Law Review, 2014, 101.

44 Véase artículo 90 de la Ley 2010 de 2019, que modificó el artículo 188 del Estatuto Tributario y que redujo la renta presuntiva al $0,5 \%$ del patrimonio líquido para el año 2020 y al $0 \%$ a partir del año 2021.

45 En las estadísticas que suministra la Superintendencia de Sociedades con base en la información contable que reportan las sociedades vigiladas se pueden observar algunas sociedades cuya du- 
Desde luego, el escenario solo será verdaderamente negativo para los preferenciales si esta sociedad muy rentable se limita a distribuir a estos últimos el dividendo mínimo estipulado estatutariamente reinvirtiendo el resto de utilidades. En tal caso, el accionista preferencial se verá impedido de disfrutar la gran rentabilidad de su inversión al no tener liquidez sus acciones ni, posiblemente, haber firmado en el pasado un acuerdo que obligue a la sociedad o a los accionistas ordinarios a comprar sus títulos (e.g., un buyout agreement).

El caso opuesto, sin duda, será peor: aquel en el cual la compañía fracasa estrepitosamente, con lo cual sí se disuelve y liquida pero sin generar remanentes para ningún tipo de accionista, ni preferencial ni ordinario, y posiblemente tampoco para muchos acreedores, como los quirografarios.

Así pues, la prelación solo será útil en casos intermedios: compañías con malos resultados financieros pero que todavía conservan parte de su patrimonio con el cual podrán reembolsar en una eventual liquidación los aportes de sus accionistas preferenciales pero no de los ordinarios.

El problema radica en que cuando una empresa está en el borde o "crepúsculo" de la insolvencia ${ }^{46}$, tanto los accionistas ordinarios como sus gestores tienen mayores incentivos para evitar a toda costa la disolución y liquidación así como para maximizar los esfuerzos por mantener a flote el negocio. Supóngase una compañía con un patrimonio de $\$ 80$ y en la que, en caso de liquidación, la prelación de los accionistas preferenciales es de \$150. Los accionistas ordinarios no ganan nada con tal liquidación y preferirán más bien, al tener una opción deep out the money, o dejar la compañía inactiva esperando que por milagro la situación mejore o, más probablemente, asumir apuestas empresariales muy arriesgadas.

Los hechos del ejemplo no son puramente teóricos sino que ya ocurrieron, al menos una vez, en el célebre caso Equity-Linked Investors, L.P. v. Adams, 705 A.2d 1040 (Del.Ch. 1997). La protagonista es Genta, una compañía del sector farmacéutico y genético que a pesar de ser propietaria de varias patentes nunca había generado utilidades, estando por el contrario al borde de la insolvencia con solo un día de liquidez para atender los pagos de capital e intereses de sus acreedores. Genta tenía tanto accionistas preferenciales como ordinarios, cuyos intereses entraron en conflicto. Si se hubiese liquidado cuando estaba a punto de cesar pagos, los preferenciales habrían recibido como reembolso buena parte de su aporte de US\$30 millones mientras que los ordinarios habrían terminado su aventura empresarial con las manos vacías.

ración, por ejemplo, va hasta el año 10.000. Véase Superintendencia de Sociedades, Portal de Información Empresarial, [en línea], disponible en: http://pie.supersociedades.gov.co/Pages/default. aspx\#/ [consultado el 16 de septiembre de 2020]. Por ejemplo, y según dicho portal, la sociedad de responsabilidad limitada con razón social Inversiones Los Posso, identificada con el NIT 891903760 y constituida en 1985, tiene una vigencia que solo expira en el año 10.007.

46 Véase Polanía, N., “Administradores e insolvencia, o 'los elementos del desastre”," [en línea], Blog de Derecho Societario, 20 de agosto de 2019, disponible en: https:/www.blogsocietario.com/post/ administradores-e-insolvencia-o-los-elementos-del-desastre [consultado el 16 de abril de 2020]. 
La junta directiva, que por supuesto los accionistas ordinarios controlaban, consideró que gracias a sus patentes Genta todavía tenía potencial empresarial y decidió intentarlo una vez más. Para ello obtuvo un préstamo garantizado por varios millones de dólares, de tal forma que, si el plan funcionaba, los accionistas ordinarios podrían pasar de tener un valor patrimonial negativo a uno positivo, mientras que la mejoría para los preferenciales sería mínima. Si el plan fracasaba, sucedería lo contrario: los accionistas ordinarios mantendrían el valor de mercado nulo de sus acciones (al menos lo habrían intentado) a la vez que los preferenciales perderían la esperanza de recuperar al menos parcialmente su inversión con motivo de la liquidación. En síntesis, la administración compró con dinero de los accionistas preferenciales un tiquete de lotería de baja probabilidad de éxito y cuyo premio, en caso de obtenerse, sería en su mayor parte para los accionistas ordinarios. Equity-Linked, uno de los accionistas preferenciales, demandó solicitando la liquidación de la compañía o la subasta de sus activos. La pregunta relevante era qué deben maximizar los administradores cuando los intereses de accionistas ordinarios y accionistas preferenciales colisionan ${ }^{47}$. La Corte de Delaware, al fallar a favor de los administradores y de los accionistas ordinarios, sostuvo que la junta directiva no había violado ningún deber legal ni al aprobar la continuidad de operaciones ni al abstenerse de sugerir a sus accionistas la liquidación, a pesar de que ello iba en contra de los intereses de los accionistas preferenciales. En particular, la Corte consideró que la célebre regla de la discrecionalidad (business judgment rule), que impide a los jueces juzgar a posteriori las estrategias administrativas, es aplicable a las decisiones sobre el momento oportuno para liquidar una compañía.

No solo para los hechos del caso citado, sino de forma más general, si una decisión en un sentido beneficia a los accionistas preferenciales y perjudica a los ordinarios, mientras que en el sentido opuesto genera el efecto contrario, ¿cuál es el deber de conducta o qué deben hacer los administradores? Estos no pueden complacer simultáneamente a ambos tipos de accionistas; al fin y al cabo, nadie puede servir a dos amos, y más si están en guerra. De hecho, la peor decisión será no hacer nada. Sobre este tema, la citada Corte de Delaware consideró que, en caso de conflicto, la junta directiva puede y debe preferir el interés de los accionistas ordinarios, como propietarios residuales, sobre el de los preferenciales ${ }^{48}$. Poco más de una década

47 Véase, en general, Bainbridge, S. M., Corporate Law, 3. a ed., New York, Foundation Press, 2015, 256 ("Jedwab does not eliminate potential conflicts of interest between the holders of preferred and common. Whose interests must the board maximize when those interest clash?").

48 Un caso ligeramente diferente es Zahn v. Transamerica Corp. 162 F.2d 36 (3d Cir. 1947). Transamerica era una compañía con grandes cantidades de inventario de hoja de tabaco cuyo valor comercial era muy superior al valor en libros. La junta directiva decidió ejercer una opción que le permitía redimir las acciones preferenciales, pagando a sus dueños un valor unitario cercano a \$80. Luego de ello, la compañía se liquidó, entregando como reembolso a los accionistas ordinarios el inventario valorizado y generándoles así una significativa ganancia. Existían otras dos opciones, no tomadas por la junta directiva. La primera consistía en revelar a todos los accionistas la valorización del inventario y la intención de liquidar, permitiendo que los preferenciales pudieran ejercer su derecho 
luego de la decisión de Equity-Linked, la Corte de Delaware ratificó esta jurisprudencia ${ }^{49}$.

En otras palabras, los accionistas preferenciales comparten el rol de beneficiarios fiduciarios de los ordinarios cuando los derechos e intereses de ambos son idénticos y alineados, como puede suceder ante violaciones por parte de administradores de sus deberes de lealtad (e.g., self-dealing) o de cuidado (e.g., malversación de fondos). En cambio, cuando los intereses de los accionistas preferenciales entran en conflicto con los de los ordinarios, aquellos tienen acciones contractuales mas no fiduciarias ${ }^{50}$. En tales situaciones, los administradores deben actuar frente a los accionistas preferenciales como lo harían con relación a empleados, proveedores,

de conversión de sus títulos en acciones ordinarias, caso en el cual recibirían una cifra mayor a la que les fue pagada. La otra opción era no informar la valorización del tabaco pero liquidar. Dada la preferencia en tal liquidación, los preferenciales hubieran recibido todavía más dinero por acción (\$240). La Corte en este caso dijo que los administradores tenían un deber fiduciario de escoger este último curso de acción. La decisión podría criticarse argumentando que si los preferenciales le habían dado a la compañía una opción de compra esta podía ejercerla en cualquier momento sin que aquellos se pudieran quejar. De todas maneras, este caso debe distinguirse de Equity-Linked, en cuanto la decisión en Zahn no era tanto empresarial como jurídica (cómo liquidar), sin que involucrase una intención de continuar un negocio. Un caso similar a Zahn es Speed v. Transamerica Corporation 235 F.2d 369 (3d. Cir. 1956). En este, la Corte dijo que el error de los administradores había sido no informar la valorización del tabaco y la intención de liquidar, pero que la junta directiva no tenía obligación de abstenerse de redimir las acciones preferenciales.

49 In re Trados Incorporated 73 A.3d 17 (Del. Ch. 2013) (reiterando que los administradores, en caso de conflicto, deben preferir los intereses de los accionistas ordinarios y, en tal sentido, considerando que podrían violar un deber fiduciario si privilegian a los accionistas preferenciales). Trados es un caso con hechos contrarios a los de Equity-Linked. En Trados, los accionistas preferenciales controlaban la junta directiva, que decidió aprobar ciertas transacciones que implicaron que los preferenciales recuperaran casi toda su inversión mientras que los accionistas ordinarios no recibieron nada. Un accionista ordinario demandó alegando que la junta directiva había violado sus deberes fiduciarios al preferir a los preferenciales sobre los comunes y la Corte le dio la razón. Otro caso relevante, aunque ya de hace más de tres décadas, es Jedwab v. MGM Grand Hotels, Inc. 509 A.2d 584 (Del.Ch.1986), sobre una fusión en la que la junta directiva de la compañía enajenante MGM decidió la distribución del beneficio generado por tal transacción entre accionistas ordinarios y preferenciales. Estos últimos objetaron la división hecha por la junta. Aunque no les dio la razón, la Corte sí observó que los preferenciales podían tener derechos fiduciarios en cuanto a que, entre otros temas, debía haber una justa (aunque no igual) repartición de los beneficios de la fusión y un cuidado apropiado en la negociación de esta. Pero véase Bainbridge, S. M., Corporate Law, 3. a ed., New York, Foundation Press, 2015, 255-256 (criticando esta decisión y afirmando que según los precedentes de la Corte de Delaware todos los derechos de los accionistas preferenciales son contractuales por naturaleza). Bainbridge también basa su argumento en un caso decidido por la Corte Suprema de Estados Unidos (Wood v. Coastal States Gas Corp. 401 A.2d 932 (Del. 1979) en el cual los preferenciales demandaron infructuosamente una escisión por supuestamente ir en contra de los estatutos de la compañía en cuestión (Coastal).

50 Para una visión escéptica e incluso contraria de esta jurisprudencia según la cual los derechos de los accionistas ordinarios priman sobre los de los preferenciales, véase NIR, S., "One duty to all: the fiduciary duty of impartiality and stockholders' conflict of interest", Hastings Business Law Journal, vol. 16, 2019, 41 ("the board of directors should consider both the interests of the common stockholders and the preferred stockholders, and balance their competing interests through the fiduciary duty of impartiality to reach a decision that would reflect the best interests of the corporation's stockholders as a whole"). 
clientes, gobierno y otros grupos de interés: con justicia, cumpliendo la ley y los contratos, pero sin tener la obligación de maximizar el valor patrimonial de su inversión ${ }^{51}$.

¿Es aplicable esta visión de la jurisprudencia estadounidense al derecho colombiano? ¿Es una visión correcta? Con relación al primer interrogante, la ley colombiana es escueta mientras que la jurisprudencia es silente. La única referencia directa sería el inciso sexto del artículo 23 de la Ley 222 de 1995, según el cual los administradores deberán "[d]ar un trato equitativo a todos los socios". Con todo, este artículo considera que tal trato igualitario a los asociados debe ser dentro de su respectiva clase, es decir y a manera de ejemplo, no preferir a unos accionistas ordinarios sobre otros, o a unos preferenciales sobre otras personas naturales o jurídicas que detenten igual clase de títulos. A contrario sensu, para accionistas diferentes podría ser necesario un trato distinto, al menos cuando los intereses de unos y otros colisionan, como acaba de ilustrarse para el caso de los accionistas ordinarios y preferenciales en compañías al borde de una crisis financiera. Después de todo, tratamiento equitativo no significa igualitario, sino dar a cada quien lo que corresponde según sus derechos y obligaciones. Esta igualdad entre iguales y posible desigualdad entre desiguales es similar a lo que ocurre en el derecho de insolvencia, donde a pesar de existir el principio de igualdad de acreedores, el mismo realmente opera exclusivamente dentro de cada clase (véase art. 4 num. 2 de la Ley 1116 de 2006) ${ }^{52}$.

En cuanto al segundo interrogante, sobre si la jurisprudencia estadounidense reflejada principalmente en el caso Equity-Linked es aplicable a Colombia, la respuesta es afirmativa. No porque así deba ser forzosamente; al fin y al cabo, el derecho extranjero no suele ser fuente formal del colombiano. Pero la lógica del razonamiento así como la ausencia de norma o jurisprudencia expresa en sentido contrario permiten afirmar que un juez en Colombia, ante unos hechos similares, podría arribar a una conclusión similar.

El vacío normativo ya se ilustró, así que solo resta detallar dicha lógica judicial. Con base en las teorías del análisis económico del derecho ${ }^{53}$, debe recordarse que el valor de la empresa se maximiza cuando las decisiones de los administradores están alineadas con las de los dueños residuales. Es decir, los administradores deben preferir a quien ocupa el último lugar en la cadena de acreedores externos e internos en lo que se refiere a la reclamación de activos de una empresa. Ello es así por cuanto el incentivo de maximizar los flujos de caja por parte de tales dueños residuales

51 Hasta 1940, la jurisprudencia estadounidense consideraba que las transacciones oportunistas o que afectaban a los accionistas preferenciales eran violatorias de sus derechos de propiedad constitucionales. Véase "Venture capital on the downside: preferred stock and corporate control", Michigan Law Review, vol. 100, n. ${ }^{\circ}$ 5, 2002, 891.

52 Véase también Rodríguez, J. J., Nuevo Régimen de Insolvencia, Bogotá, Universidad Externado de Colombia, 2019., así como Londoño, A. e IsazA, A., Comentarios al Régimen de Insolvencia Empresarial, 3. ed., Bogotá, Legis, 2008.

53 Véase, p. ej., Bainbridge, S. M., Corporate Law and Economics, New York, Foundation Press, 2002. 
(accionistas), y salvo un fracaso estruendoso de tales acciones, significa que todos los demás grupos de interés van a recibir las sumas prometidas en sus respectivos contratos.

El tema se puede entender todavía mejor en el escenario contrafáctico. ¿Qué pasaría si la ley dice que en caso de conflicto los administradores deben preferir a los accionistas preferenciales? Tal como ya se afirmó en otro apartado de este texto, a los administradores les bastaría con generar las mínimas utilidades requeridas para satisfacer a los accionistas preferenciales, lo que podrían lograr invirtiendo los recursos en actividades tradicionales, poco innovadoras y de bajo riesgo. De esta manera se limitaría gravemente la asunción de riesgo inherente a la actividad empresarial, generando compañías que rinden solo una fracción de su potencial o, peor aún, casos de liquidación de sociedades a pesar de que estas tienen proyectos con valor presente neto positivo.

Así pues, los accionistas preferenciales tienen prelación financiera sobre los ordinarios pero, y por esa misma razón, son estos últimos los que deben tener preferencia sobre aquellos en relación con decisiones que beneficien a unos y perjudiquen a otros. ¿Este estatus inferior con relación al de los accionistas ordinarios hace que no se justifique emitir y suscribir acciones preferenciales y sin derecho a voto?

Realmente, y dejando de lado las siete compañías que actualmente tienen inscritas acciones preferenciales en la Bolsa de Valores de Colombia ${ }^{54}$, este tipo de títulos son escasos en nuestro país ${ }^{55}$. No hay estadísticas sobre su número en sociedades cerradas, pero la Superintendencia de Sociedades, en comunicación con radicado 2019-01-361921, fechada el 30 de octubre de 2019 y como respuesta a un derecho de petición enviado por el autor, informó que en los últimos cinco años no se han autorizado colocaciones de acciones preferenciales sin derecho a voto ${ }^{56}$. Es verdad que tal autorización no se requiere para todas las compañías, sino solo en el caso de sociedades vigiladas o controladas por la Superintendencia de Sociedades (art. 84

54 Las siete acciones preferenciales son las identificadas como PFBCOLOM, PFGRUPOARG, PFAVAL, PFDAVVNDA, PFGRUPSURA, PFAVH y PFCEMARGos. Véase Bolsa de Valores de Colombia, [en línea], disponible en: https://www.bvc.com.co/pps/tibco/portalbvc/Home/Mercados/enlinea/acciones [consultado el 16 de abril de 2020].

55 En Estados Unidos, las acciones preferenciales y sin derecho a voto son comunes en las compañías de capital de riesgo (venture capital) o en compañías tecnológicas denominadas start-ups. En compañías en bolsa son poco comunes y están en declive desde la última parte del siglo xx, salvo en tratándose de compañías sujetas a reglas estrictas de capitales mínimos, como instituciones financieras o compañías de servicios públicos, que al contar con patrimonios muy altos representan un menor riesgo financiero para los accionistas preferenciales. Véase Bratton, W. W., "Venture capital on the downside: preferred stock and corporate control", cit., 891. Véase también NIR, S., "One duty to all: the fiduciary duty of impartiality and stockholders' conflict of interest", Hastings Business Law Journal, vol. 16, 2019, 41.

56 Un aparte de la respuesta dice así: "Respetado señor [...]: Se recibió su escrito radicado con el número del asunto por medio del cual solicita que se le indique lo siguiente: [...] 3. Número de autorizaciones de colocación de acciones con dividendo preferencial y sin derecho a voto. Sobre el particular, le informo que este Despacho cuenta con estadísticas de los últimos 5 años en los cuales respecto de los primeros tres puntos de su escrito, no se han atendido solicitudes". 
num. 9 de la Ley 222 de 1995, Decreto 1074 de 2015 y Circular Básica Jurídica n. ${ }^{\circ}$ 100-000005 del 22 de noviembre de 2017). Pero tal ausencia de casos en relación con una muestra significativa de sociedades sugiere que el número y valor de las acciones preferenciales sin derecho a voto es muy bajo en Colombia.

De hecho, la aparente escasez de acciones preferenciales genera el interrogante de si su poco uso se debe a los riesgos ya descritos en la presente sección. Benjamin Graham, el mentor del famoso inversionista Warren Buffet, afirmó hace varias décadas que el rendimiento de una acción preferencial casi nunca justifica el riesgo de maltrato por parte de la junta directiva ${ }^{57}$.

A pesar de las desventajas de las acciones preferenciales y de que estas hacen más riesgosa la labor de los administradores, la visión no debe ser tan pesimista. Por el contrario, este texto considera que las acciones preferenciales, en ciertos contextos de negocios y con las debidas protecciones estatutarias, pueden ser útiles tanto para sus titulares como para los accionistas ordinarios al combinar en una misma sociedad asociados cuyos intereses en cuanto al voto y al riesgo del retorno de la inversión difieren. A pesar de tal utilidad, su escasez en Colombia, hecho que se trata de paso por no ser el tema central del artículo, puede deberse en parte a la ignorancia sobre su existencia o bondades, a la excesiva aversión a sus riesgos o a la poca innovación legal de los empresarios y de sus abogados.

En otras palabras, hay estrategias viables para mantener los beneficios de las acciones preferenciales a la par que se reducen o protegen los riesgos existentes. Una primera protección consiste en que los accionistas preferenciales tengan una opción, sujeta a plazo o condición, de convertir sus acciones en ordinarias. Una segunda posibilidad es que tales asociados tengan la opción de exigirles a los accionistas ordinarios o a la compañía recomprar sus acciones si ocurren ciertos eventos, como por ejemplo: (i) ausencia de utilidades durante $\mathrm{X}$ número de años, (ii) una extensión del término de vigencia de la sociedad o (iii) una decisión de no disolver a pesar de que el patrimonio ha disminuido en Y porcentaje ${ }^{58}$. Lamentablemente, la opción de exigirle a la compañía la recompra de acciones cuando ocurra cierto evento podría no funcionar bien en Colombia, ya que el artículo 396 c.com. exige, equivocadamente ${ }^{59}$, que la readquisición se financie con una reserva

57 Graham, B. y Dodd, D., Security Analysis, The Classic 1940, cit., 184-206, 261-265.

58 Los accionistas mayoritarios podrían exigir, a cambio, un derecho similar: tener la opción de recomprar las acciones preferenciales. Por ejemplo, cuando las tasas de interés han bajado y sea rentable sustituir tales acciones preferenciales por deuda. Véase BEN, W., "The peril and promise of preferred stock", Delaware Journal of Corporate Law, vol. 39, n. ${ }^{\circ}$ 1, 2015, 161-176.

De otro lado, en Estados Unidos, y especialmente en negocios de capital de riesgo, suele ser común que los preferenciales puedan exigir a la compañía la recompra de sus acciones cuando ha pasado cierto número de años sin que esta haya realizado una oferta pública de acciones en el mercado de valores, la cual generaría liquidez para los títulos de la empresa. Véase Bratton, W. W., "Venture capital on the downside: preferred stock and corporate control", cit., 891.

59 Al no ser el tema central de este texto, las razones por las cuales exigir una reserva derivada de utilidades del ejercicio es una política legislativa equivocada se dejan para un futuro artículo. 
tomada de las utilidades líquidas. Si tales utilidades no existen, no será posible la recompra por parte de la sociedad, a menos que se apruebe una reducción del capital, la cual y según el artículo 145 c.com. deberá ser autorizada previamente por la Superintendencia de Sociedades, lo que solo sucederá cuando la compañía en cuestión no tiene pasivo externo, este es menos de la mitad de los activos luego de hecha la reducción de capital o, en caso contrario, todos los acreedores aceptan la reducción, todo ello sin perjuicio del permiso de la autoridad laboral cuando parte del pasivo corresponde a prestaciones sociales. Un requisito ya no legal sino financiero de la reducción de capital (o también de la prima en colocación de acciones) consiste en que el monto a reembolsar a los accionistas preferenciales salientes debe ser inferior al valor de tales cuentas patrimoniales. Si la reducción de capital no es viable legal o financieramente, la alternativa sería obligar a que los accionistas ordinarios compren las acciones preferenciales. El riesgo en tales casos consiste en que los accionistas mayoritarios y sus administradores actúen de mala fe con el fin de no generar utilidades durante cierto tiempo y así presionar tal compraventa a bajo precio.

Una tercera protección sería pactar restricciones estatutarias o contractuales para los administradores y accionistas ordinarios que reduzcan los riesgos de expropiación y de exclusión, aunque a costa de incrementar las expensas de transacción y monitoreo. Por ejemplo, limitaciones relacionadas con fusiones, sustitución de activos de menor riesgo por otros de mayor contingencia o recapitalizaciones apalancadas que diluyan o excluyan a los accionistas preferenciales. Con todo, se reconoce que esta opción es más teórica que práctica toda vez que tales restricciones implicarían un derecho de veto para los accionistas preferenciales que contradice su renuncia al voto.

Una última opción es estipular cláusulas estatutarias que otorguen a los accionistas preferenciales derechos de voto cuando se cumplan ciertas condiciones. Los artículos 63 y 64 de la Ley 222 de 1995 otorgan derecho a voto a los preferenciales en ciertos casos, pero tales disposiciones, aunque bien intencionadas, resultan inocuas, en la mayoría de los casos por limitaciones legales y prácticas. En efecto, los accionistas preferenciales en sociedades diferentes a una SAS no pueden tener más del 50\% del capital (art. 61 de la Ley 222 de 1995). En la sAs es posible una cifra superior, aunque sería raro que tal situación se presentara. Así las cosas, y en la mayoría de casos, los accionistas preferenciales obtendrían derechos de voto inferiores al 50\% de los sufragios totales, cifra insuficiente para imponer su voluntad. En otras palabras, el derecho al voto otorgado a los accionistas preferenciales solo sirve, realmente, cuando permite a una sola persona, o a varias de ellas que estén alineadas, obtener una mayoría. Los estatutos podrían estipular que si determinadas condiciones se cumplen, los preferenciales podrían tener la mayoría de votos o al menos un derecho de veto sobre ciertas decisiones; aunque es verdad que sería difícil que los accionistas ordinarios aceptasen tales cláusulas sin recibir nada a cambio. 


\section{Responsabilidad de los administradores en sociedades en las que coexisten acciones ordinarias y otro tipo de acciones diferentes a las de voto múltiple y a las preferenciales sin derecho a voto}

Las acciones de voto múltiple y las preferenciales sin derecho a voto no son los únicos títulos que pueden coexistir con acciones ordinarias y generar posibles responsabilidades para los administradores sociales. Lo propio puede ocurrir con las acciones privilegiadas, las de seguimiento y las de pago. Los siguientes párrafos analizan la responsabilidad de los administradores cuando existen tales tipos de acciones, aunque de manera muy breve dadas las limitaciones de espacio y debido igualmente a que el énfasis se hizo en acciones de voto múltiple y preferenciales sin derecho a voto.

Desde el inicio de su vigencia en 1971, el artículo 381 c.com. permitió las acciones privilegiadas, y lo propio hizo el artículo 10 de la Ley 1258 casi cuatro décadas más tarde en el caso de las sas. Tales acciones privilegiadas otorgan a sus dueños: (i) un derecho preferencial para su reembolso en caso de liquidación, aunque solo hasta el valor nominal, y (ii) un derecho con duración no mayor a cinco años a tener una preferencia acumulable o no en las utilidades, así como cualquier otra prerrogativa de carácter económico que se estipule estatutariamente.

Aunque no se cuenta con estadísticas, la intuición del autor es que las acciones privilegiadas son prácticamente inexistentes, y ello a pesar de que han sido viables legalmente durante casi medio siglo ${ }^{60}$. Las razones para tal fracaso son fáciles de descifrar. La más importante es que para los accionistas ordinarios no tiene mucho sentido dar una preferencia a los privilegiados sin recibir nada a cambio, no hay un quid pro quo, como sí sucede con relación a las acciones preferenciales sin derecho a voto (preferencia a cambio de renunciar al voto). Era una época, cuando el código de comercio se promulgó, en la que era anatema pensar que una acción no generara derechos políticos. Además de ello, poco interés despiertan unas acciones que solo pueden tener prelación para el pago de dividendos por períodos de cinco años y cuya preferencia para liquidación es solo hasta el monto nominal y no hasta el valor contable o de mercado de los activos.

De manera similar a lo que ocurre cuando hay acciones preferenciales, los intereses de los accionistas ordinarios y de los privilegiados podrían divergir: aquellos podrían preferir empresas más riesgosas y estos últimos actividades más seguras. Para mantener la coherencia argumental del presente texto se debe interpretar que en

60 Andrés Moreno reporta en su libro sobre la historia de la Bolsa de Valores de Colombia que si bien actualmente no hay ninguna acción privilegiada que cotice allí, en el pasado sí han existido, con emisores como Isagen, ETB e ISA. Véase Moreno, A., La bolsa en Colombia en el siglo XXI, la evolución de los inversionistas y emisores de acciones de la Bolsa de Colombia en los últimos 20 años (1999-2018), Bogotá, 2018. 
caso de tal conflicto los administradores han de preferir los intereses de los accionistas ordinarios, como dueños residuales de la compañía.

El artículo 10 de la Ley 1258 de 2008, sin mencionarlas expresamente, permite las acciones de clase, denominadas tracking shares en el derecho comparado ${ }^{61}$. "De clase" significa que una sociedad ha emitido al menos dos tipos de acciones, A y $\mathrm{B}$, dando cada una de las clases derecho a las utilidades de una línea o división del negocio dentro de un mismo vehículo jurídico. Tales acciones de clase pueden tener ventajas, como evitar una escisión cuando su único objetivo es separar líneas de negocio, aunque a costa de una mayor complejidad contable, dado que se requerirá separar debidamente gastos comunes ${ }^{62}$. Las acciones de clase también son útiles cuando los accionistas tienen intereses diferentes y aportan trabajo de manera disímil a la compañía, lo que suele ser común en empresas de prestación de servicios inherentes a las profesiones liberales, como la medicina o el derecho. Piénsese en una clínica con médicos de todas las especialidades como accionistas y en la cual, verbigracia, los cardiólogos no quieren que los urólogos participen en las utilidades generadas por las cirugías de corazón abierto mientras estos no quieren que aquellos reciban ingresos por cirugías de uretra o riñón.

Desde la perspectiva de la responsabilidad de los administradores, el riesgo es que estos dediquen más tiempo o esfuerzo a una línea de negocios que a otra, con lo cual beneficiarían a los accionistas de, dígase, la clase A, pero perjudicarían a los de la clase B. Estos últimos, si el perjuicio económico es grande, podrían demandar alegando violación derechos fiduciarios. Los administradores también deberán ser mucho más cuidadosos con la información contable cuando hay acciones de clase, toda vez que de ella depende la manera de distribuir las utilidades entre los diferentes negocios de la firma. A diferencia de las acciones preferenciales sin derecho a voto, todos los tipos de accionistas de clase son dueños residuales y, consecuentemente, los administradores no deberían privilegiar a ninguno de ellos sobre los demás, aunque, por la diferencia de incentivos entre accionistas y por las complejidades contables ya descritas, esta será una tarea más difícil para los administradores en comparación con sociedades en las cuales todas las acciones son idénticas. Estos administradores, al estar muchas veces sometidos a presiones contrarias, asumirán mayor riesgo, razón por la cual tendrían derecho a exigir una mayor remuneración.

Solo resta por hacer referencia a la responsabilidad de los administradores cuando una sociedad ha emitido acciones de pago. Estas, mencionadas por el artículo 10

61 Véase, en general, SANín, J. E., “Las 'acciones de seguimiento' en el derecho societario colombiano", [en línea], El Mundo, 15 de julio de 2018, disponible en: http://www.isanin.com.co/es/lasacciones-de-seguimiento-en-el-derecho-societario-colombiano/ [consultado el 2 de julio de 2020].

62 Por ejemplo, Ат\&т distribuyó en el año 2000 un dividendo en acciones ligadas exclusivamente a su negocio inalámbrico, aunque un año después trasladó este a una nueva compañía mediante una escisión. Dada su baja popularidad con los inversionistas, esta fue tal vez la última emisión de este tipo de acciones en el mercado de valores. Véase Brealey, R. A., Myers, S. y Allen, F., Principles of Corporate Finance, 12. ${ }^{\mathrm{a}}$ ed., New York, McGraw-Hill, 2017, 849. 
de la Ley 1258 de 2008 pero realmente permitidas para cualquier tipo de sociedad al ser el fruto de aportes en especie, son las que se emiten a los nuevos asociados como parte de pago por una labor o servicio prestado. Cualquier tipo de enajenantes de bienes o prestadores de servicios pueden recibir su pago en acciones de la compañía adquirente, aunque lo usual es que quienes reciban tales títulos sean sus administradores, especialmente porque, al convertirlos en accionistas, la sociedad les da un incentivo para maximizar las utilidades, reduciendo así el problema de agencia entre asociados y gestores ${ }^{63}$. Las acciones de pago podrán ser ordinarias o de cualquier otro tipo permitido por la ley ${ }^{64}$.

Como comentario final, las acciones de pago, al convertir a los administradores en accionistas, generan la consecuencia natural de incrementar las decisiones en las que tales personas estarán inmersas en conflictos de intereses (art. 23 num. 7 de la Ley 222 de 1995). Tales conflictos han sido muy estudiados cuando el administrador es un accionista mayoritario pero no tanto cuando, como suele pasar en estos casos, es minoritario.

\section{Conclusiones}

Este texto conceptuó que los administradores deben dar prelación a los accionistas ordinarios sobre los preferenciales y los privilegiados, teniendo derechos fiduciarios frente a aquellos pero no ante estos cuando los intereses de unos y otros entran en conflicto. Si los intereses de ambos tipos de accionistas están alineados, no habrá dificultades en afirmar que los administradores deben procurar el beneficio de ambos tipos de asociados.

En contraste, los administradores deben mantenerse fieles al postulado tradicional de no preferencia entre accionistas cuando los ordinarios conviven con accionistas con voto múltiple o cuando hay acciones de clase. Finalmente, las acciones de pago, cuando son entregadas a los administradores, hacen que estos tengan la doble calidad de gestores y accionistas, lo que aumenta las decisiones que deberán tomar bajo conflictos de intereses. El tratamiento preferencial o no de los administradores con respecto a los accionistas de pago, especialmente cuando estos son terceros, dependerá de si tales títulos corresponden a acciones ordinarias o a otro tipo de acciones, como de voto múltiple, preferenciales sin derecho a voto, de dividendo fijo, privilegiadas o de clase.

El tema tratado en este texto es novedoso y relevante porque va más allá de la tradicional discusión acerca de si los administradores deben preferir a los accionistas sobre los demás grupos de interés o tratar a unos y otros por igual, debatiendo qué

63 Brealey, R. A., Myers, S. y Allen, F., Principles of Corporate Finance, 12. a ed., New York, McGraw-Hill, 2017, 849.

64 Véase Oficio 220-23629 de la Superintendencia de Sociedades del 30 de marzo del 2000 sobre acciones con dividendo preferencial suscritas por empleados y pagadas con aporte de industria. 
sucede cuando hay diversas jerarquías de asociados. En tal sentido, este texto busca ser el primero en analizar, bajo las normas colombianas, los desafíos que para la responsabilidad de los administradores genera tal coexistencia de diversos accionistas.

Aunado a lo anterior, el tema estudiado no es solo pertinente por su relevancia y porque estimula la discusión académica y jurídica, sino también porque sirve de ilustración de muchos problemas novedosos que surgirán en cuanto a responsabilidad de los administradores en los próximos años, no limitados al ámbito de diferentes clases de acciones, y que irán más allá de las tradicionales discusiones sobre deberes de lealtad y de cuidado o de conflictos de intereses.

\section{Referencias}

Armour, J., Enriques, L., Pargendler, M. y Ringe., W. G., "Beyond the anatomy", en Krankman, R. (ed.), The Anatomy of Corporate Law. A Comparative and Functional Analysis, 2. ${ }^{\text {a }}$ ed., Oxford, Oxford University Press, 2009.

Atanasov, V., Black, B. у Ciccotello, C., "Unbundling and measuring tunneling”, University of Illinois Law Review, 2014, 101.

Bainbridge, S. M., Corporate Law and Economics, New York, Foundation Press, 2002.

Bainbridge, S. M., Corporate Law, 3. a ed., New York, Foundation Press, 2015.

Bebchuk, L. A. y Kastiel, K., “The perils of small minority controllers”, Law Working Paper - ECGI Working Paper Series in Law, n. ${ }^{\circ}$ 434, 2018.

Bebchuк, L. A. y Kastiel, K., "The untenable case for perpetual dual class stock", Virginia Law Review, vol. 103, n. ${ }^{\circ}$ 4, 2017, 585.

Bebchuk, L. A., Kraakman, R. y Triantis, G., "Stock pyramids, cross-ownership and dual class equity: the mechanisms and agency costs of separating control from cash-flow rights", en Morck, R. (ed.), Concentrated Corporate Ownership, New York, University of Chicago Press, 2000, 445-460.

BEN, W., "The peril and promise of preferred stock", Delaware Journal of Corporate Law, vol. 39, n. ${ }^{\circ} 1,2015,161-176$.

Berle, A. A. y Means, G. C., The Modern Corporation and Private Property, 2. . ed., New York, Routledge, 1991. 
Bratton, W. W., "Venture capital on the downside: preferred stock and corporate control”, Michigan Law Review, vol. 100, n. ${ }^{\circ}$ 5, 2002, 891.

Brealey, R. A., Myers, S. y Allen, F., Principles of Corporate Finance, 12. a ed., New York, McGraw-Hill, 2017.

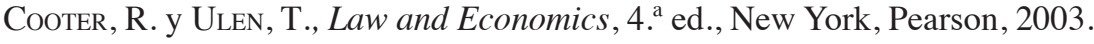

Gaviria, E., Nuevo régimen de sociedades, comentario general, Medellín, Diké, 1996.

Goshen, Z. y Hamdani, A., "Corporate control, dual class, and the limits of judicial review", Columbia Law Review, vol. 120, n. ${ }^{\circ}$ 941, $2020,94$.

Graham, B. y Dodd, D., Security Analysis, The Classic 1940, 2. ${ }^{a}$ ed., New York, McGraw Hill, 2019.

Gurrea-Martínez, A., "Theory, evidence, and policy on dual-class shares: a country-specific response to a global debate", Ibero-American Institute for Law and Finance, Working Paper Series n. ${ }^{\circ}$ 3, 2019.

Johnson, S., La Porta, R., Lopez, F. y Shleifer, A., "Tunneling”, The American Economic Review, vol. 90, n. ${ }^{\circ}$ 2, 2000, 22-27.

Kim, H. y Michaely, R., "Sticking around too long? Dynamics of the benefits of dual-class voting", [en línea], European Corporate Governance Institute (ECGI) - Finance Working Paper n. ${ }^{\circ}$ 90, 2019, disponible en: https://ecgi.global/working-paper/sticking-around-too-long-dynamics-benefits-dual-class-voting [consultado el 16 de septiembre de 2020].

Kinsley, M.(ed.), Creative Capitalism. A Conversation, New York, Simon \& Schuster, 2008.

La Porta, R. Lopez, F., Shleifer, A. y Vishny, R., "Law and finance”, Journal of Political Economy, vol. 106, n. ${ }^{\circ}$ 6, 1998, 1113.

Londoño, A. e Isaza, A., Comentarios al Régimen de Insolvencia Empresarial, 3. ed., Bogotá, Legis, 2008.

Mayer, C., Prosperity: Better Business Makes the Greater Good, Oxford, Oxford University Press, 2019 
Moreno, A., La bolsa en Colombia en el siglo XXI. La evolución de los inversionistas y emisores de acciones de la Bolsa de Colombia en los últimos 20 años (19992018), Bogotá, 2018.

NIR, S., "One duty to all: the fiduciary duty of impartiality and stockholders' conflict of interest", Hastings Business Law Journal, vol. 16, 2019, 41.

Puyo, R., "Los diez grandes capítulos de la legislación de las sociedades comerciales en Colombia”, en ReYes, F. (coord.), Estudios sobre la sociedad por acciones simplificada, Bogotá, Universidad Externado de Colombia, 2010, 247-295.

REYES, F., La sociedad por acciones simplificada, Bogotá, Legis, 2009.

Rodríguez, J. J., Nuevo Régimen de Insolvencia, Bogotá, Universidad Externado de Colombia, 2019.

SABOGal, L. F., "El 'interés social': apuntes teóricos en el marco socio-económico del derecho de empresa", Revista e-mercatoria, n. ${ }^{\circ} 10,2011$.

SANín, I., "La Ley SAS remoza las sociedades comerciales (y crea, también, nuevos retos)", en REYEs, F. (ed.), Estudios sobre la sociedad por acciones simplificada, Bogotá, Universidad Externado de Colombia, 2012, 62-64.

Sanín, I., Un nuevo derecho societario, el propuesto desde el Estatuto Tributario, Medellín, Diké, 1999.

Sharfman, B. F., "The undesirability of mandatory time-based sunsets in dual class share structure: a reply to Bebchuk and Kastiel", Southern California Law Review Postscript, vol. 93, 2019, 1.

Stout, L., The Shareholder Value Myth: How Putting Shareholders First Harms Investors, Corporations, and the Public, New York, Berrett-Koehler, 2012.

\section{Documentos recuperados de internet}

Bolsa de Valores de Colombia, [en línea], disponible en: https://www.bvc.com.co/ pps/tibco/portalbvc/Home/Mercados/enlinea/acciones [consultado el 16 de abril de 2020].

Business Roundtable, "Business Roundtable redefines the purpose of a corporation to promote 'an economy that serves all americans"”, [en línea], agosto 19, 2019, disponible en: https://www.businessroundtable.org/business-roundtable- 
redefines-the-purpose-of-a-corporation-to-promote-an-economy-that-servesall-americans [consultado el 16 de abril de 2020].

Capitalism The Great Debate - Stakeholder v. Shareholder, [en línea], Youtube, disponible en: https://www.youtube.com/watch?v=cUpyL1zVF50 [consultado el 2 de julio de 2020].

FriedMAN, M. "The social responsibility of business is to increase its profits", [en línea], The New York Times Magazine, 1970, disponible en: http://umich. edu/ thecore/doc/Friedman.pdf [consultado el 2 de julio de 2020]

Mendoza, J. M., “La comandita: R. I. P.”, [en línea], Ámbito Jurídico, 4 de julio de 2019, disponible en: https://www.ambitojuridico.com/noticias/columnistaimpreso/sociedades-y-economia-solidaria/la-comandita-r-i-p [consultado el 2 de julio de 2020].

Polanía, N., "Administradores e insolvencia, o "los elementos del desastre"”, [en línea], Blog de Derecho Societario, 20 de agosto de 2019, disponible en: https:// www.blogsocietario.com/post/administradores-e-insolvencia-o-los-elementosdel-desastre [consultado el 16 de abril de 2020].

Revista Dinero, “La reivindicación de los accionistas minoritarios”, [en línea], disponible en: https://www.dinero.com/empresas/articulo/como-proteger-a-losaccionistas-minoritarios/276511 [consultado el 16 de abril de 2020].

REyes, F., "Corporate governance in Latin America, a functional analysis", [en línea], Inter-American Law Review, vol. 39, n. . 2, 2008, disponible en: http://ssrn. com/abstract $=1005208$ [consultado el 16 de abril de 2020].

SANín, J. E., "Las 'acciones de seguimiento' en el derecho societario colombiano", [en línea], El Mundo, 15 de julio de 2018, disponible en: http://www.isanin. com.co/es/las-acciones-de-seguimiento-en-el-derecho-societario-colombiano/ [consultado el 2 de julio de 2020].

\section{Jurisprudencia}

Colombia. Superintendencia de Sociedades. Sentencia del 20 de octubre de 2019. Gina Maritza Leguizamón Barbosa versus Luz Amanda Leguizamón Barbosa, Rolando Leguizamón Barbosa e Inversiones Leguizamón Barbosa \& Cía. S. en C.

Estados Unidos. In re Trados Incorporated Shareholder Litigation 73 A.3d 17 (Del. Ch. 2013). 
Estados Unidos. Jedwab v. MGM Grand Hotels, Inc. 509 A.2d 584 (Del.Ch.1986).

Estados Unidos. Equity-Linked Investors, LP v. Adams 705 A.2d 1040 (1997).

Estados Unidos. Wood v. Coastal States Gas Corp. 401 A.2d 932 (Del. 1979).

Estados Unidos. Bove v. Community Hotel Corp. 105 R.I. 36 (R.I. 1969).

Estados Unidos. Speed v. Transamerica Corp. 235 F.2d 369 (3d. Cir. 1956).

Estados Unidos. Zahn v. Transamerica Corp. 162 F.2d 36 (3d Cir. 1947).

Estados Unidos. Dodge v. Ford Motor Co., 204 Mich. 459, 170 N.W. 668 (Mich. 1919).

\section{Oficios de la Superintendencia de Sociedades}

Oficio 220-23629 de 2000.

Oficio 220-43349 de 2001.

Oficio 220-43152 de 2001.

Oficio 220-087094 de 2009.

Oficio 220-081657 de 2009

Oficio 220-085176 de 2009.

Oficio 220-057533 de 2009.

Oficio 220-05723 de 2015.

Oficio 220-136893 de 2018. 